\title{
Epidemiological profile of health-care-associated infections in the central-east area of Tunisia
}

K. Ben Salem, ${ }^{1}$ S. ElMhamdi, ${ }^{1}$ M. Letaief, ${ }^{1}$ M. Bchir ${ }^{1}$ and M.S. Soltani ${ }^{7}$

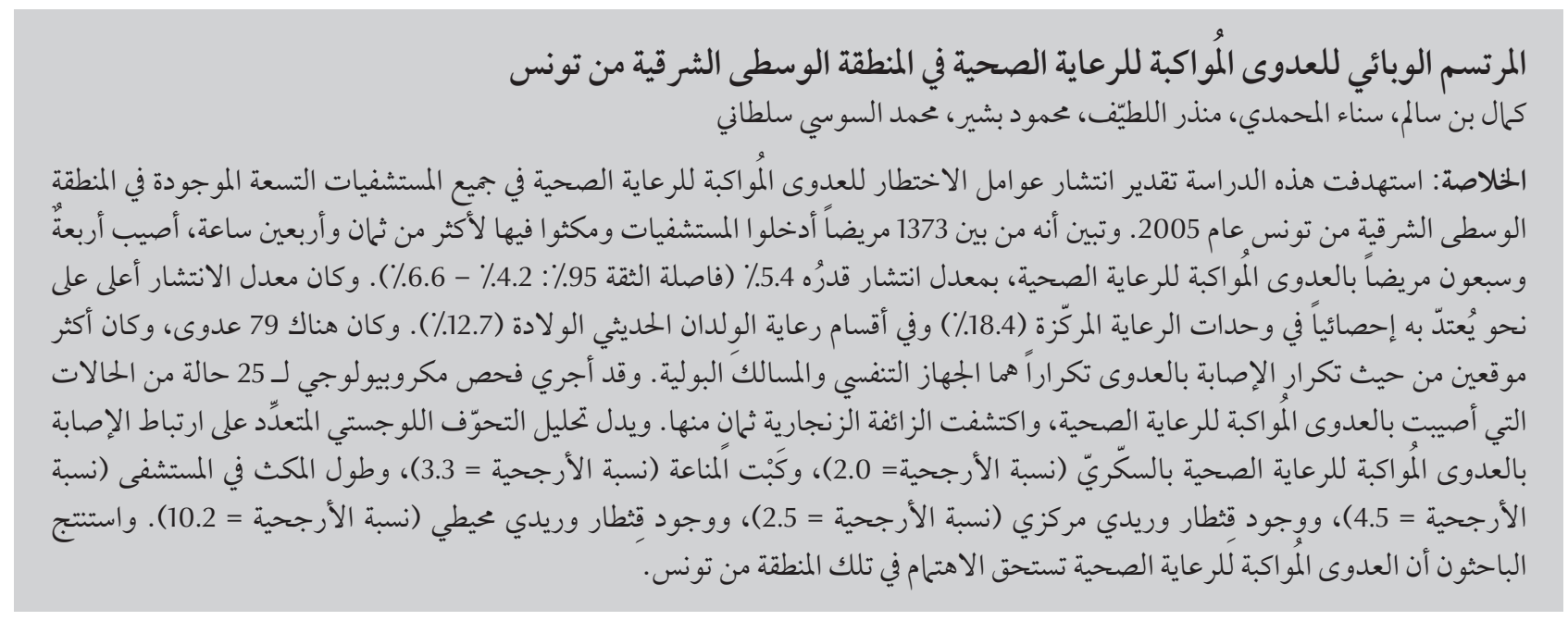

ABSTRACT This study aimed to estimate the prevalence and risk factors for health-care-associated infection (HAI) in all 9 hospitals of the central-east area of Tunisia in 2005. Of 1373 patients admitted for more than 48 hours, 74 developed $\mathrm{HAI}$, a prevalence of $5.4 \%$ (95\% $\mathrm{Cl}: 4.2 \%-6.6 \%)$. The prevalence was significantly higher in the intensive care units (18.4\%) and neonatal departments (12.7\%). There were 79 infections and the most frequent sites of infection were respiratory tract and urinary tract. Microbiological examination was performed for 25 cases of $\mathrm{HAl}$ and Pseudomonas aeruginosa was identified in 8 cases. Multiple logistic regression analysis indicated that $\mathrm{HAI}$ was linked to diabetes $(\mathrm{OR}=2.0)$, immunosuppression $(\mathrm{OR}=3.3)$, length of stay $(\mathrm{OR}=4.5)$, central venous catheter $(O R=2.5)$ and peripheral venous catheter $(O R=10.2)$. We conclude that HAIs are of concern in this area of Tunisia.

Profil épidémiologique des infections liées aux procédures de soins dans la région du centre-est de la Tunisie

RÉSUMÉ La présente étude visait à estimer la prévalence et les facteurs de risque des infections liées aux procédures de soins dans tous les hôpitaux de la région du centre-est de la Tunisie, comptant neuf établissements, en 2005. Sur un total de 1373 patients séjournant depuis plus de 48 heures à l'hôpital, 74 ont présenté une infection associée aux procédures de soins, correspondant à une prévalence de 5,4 \% (IC à 95 \% : 4,2 \%-6,6 \%). La prévalence était nettement plus élevée dans les unités de soins intensifs (18,4\%) et les services de néonatalogie $(12,7 \%)$. Au cours de l'étude, 79 infections ont été observées et les sites d'infection les plus fréquents étaient les voies respiratoires et urinaires. Une analyse microbiologique a été réalisée pour 25 cas d'infections liées aux procédures de soins et Pseudomonas aeruginosa a été identifié dans 8 cas. Une analyse de régression logistique multiple a indiqué que les infections associées aux procédures de soins étaient liées aux variables suivantes : diabète $(O R=2,0)$, immunodépression $(O R=3,3)$, durée du séjour $(O R=4,5)$, pose d'un cathéter veineux central $(O R=2,5)$ ou d'un cathéter veineux périphérique $(O R=10,2)$. Nous en concluons que les infections liées aux procédures de soins constituent un motif de préoccupation dans cette région de Tunisie. 


\section{Introduction}

Nosocomial or health-care-associated infection (HAI) is an important cause of patient's morbidity and mortality [1]. In recent years, it has become more prominent due to the greater complexity of hospital patients' conditions and to developments in health care, which in some institutions has led to patients becoming more vulnerable to infection. As an adverse outcome of acute hospital care, HAI can be used as a quality indicator for the overall assessment of hospital treatment [2].

Surveillance for HAI is an essential part of infection control and has been widely accepted throughout the world as a primary step for prevention. To accomplish this, prevalence surveys can be used to quantify the burden of disease and to help establish priorities [3]. A study in Morocco reported on the prevalence of hospital-acquired infection in a university hospital [4]. In nearby Tunisia, in order to establish infection control programmes and select priorities, we need to assess the magnitude of HAI in the local context and to identify the major associated factors. In our case, to scope and assess the magnitude of the problem of HAI and to establish control priorities we carried out a prevalence survey of HAI in hospitals in the central-east region of Tunisia as a part of the national prevalence survey (NOSOTUN05).

\section{Methods}

\section{Sample}

All health care facilities in the centraleast region of Tunisia were invited to participant in a cross-sectional study. A total of 9 hospitals participated: 4 teaching hospitals, 3 regional hospitals and 2 private clinics.

Each department was visited on one day. All inpatients present on the day of the study who had a hospital stay exceeding 48 hours were included ( $n$
$=1373$ patients). Data were collected continuously over the 2-month period January and February 2005.

\section{Data collection}

A trained public health doctor and a senior technician in hospital hygiene were in charge of data collection in each hospital. The data collection schedule of the investigators was unknown to hospital officials.

Three datasheets (hospital, department and patient) were designed for data collection. Data entry was anonymous. The hospital and department datasheets were used to collected data on the duration of stay for each patient, department of admission and the specialty (medical or surgical). In the patients' datasheet we collected data on age and sex; intrinsic risk factors for HAI (malnutrition, diabetes, neutropenia, immunosuppression and obesity); extrinsic risk factors (urinary catheter, parenteral nutrition, mechanical ventilation, central and peripheral venous catheter); site of infection; antibiotic use; and microorganisms isolated and resistance pattern.

In the surgery department, we collected information for each patient who underwent surgery about: the degree of urgency; the American Society of Anesthesiology (ASA) physical status score [5]; the Altemeier contamination classification [6]; and the use of antibiotic prophylaxis.

\section{Definitions}

We adopted the US Centers for Disease Control and Prevention (CDC) definition of HAI [7] as a localized or systemic condition resulting from an adverse reaction to the presence of an infectious agent (s) or its toxin(s) when there is no evidence that the infection was present or incubating at the time of admission to the acute care setting. HAIs may be caused by infectious agents from endogenous or exogenous sources. In the current study only clinically or microbiologically documented cases were considered as positive for HAI.

The following definitions were used: obesity was body mass index $>30 \mathrm{~kg} /$ $\mathrm{m}^{2}$, malnutrition was body mass index $<17 \mathrm{~kg} / \mathrm{m}^{2}$; neutropoenia was $<2000$ neutrophils/ $\mu \mathrm{L}$ of blood; diabetes was glycemic index $>1.26 \mathrm{~g} / \mathrm{L}$; immunosuppression was $\mathrm{CD} 4$ count $<500 \mathrm{~mm}^{3}$.

\section{Data analysis}

Analyses were performed using Epi-info software, version 6.0. The analysis of factors associated with HAI was based on appropriate statistical tests (Student ttest to compare means, non-parametric tests when a normal distribution of data could not be assumed and chi-squared test for the comparison of percentages). A $P$-value $<0.05$ was considered to be statistically significant. Variables with univariate test value $\leq 0.25$ were included in a multivariate stepwise logistic regression to control for the effect of confounding variables. In the final model we identified the factors independently associated with HAI.

\section{Results}

\section{Patients' demographic and clinical characteristics}

The overall majority of the study patients (95.5\%) were hospitalized in the university hospitals. Their mean age was 46.4 (standard deviation 22) years, with extremes ranging from 1 day to 91 years and the sex ratio was 1.07.

The median length of stay between patient admission in each department and the date of the inquiry was 7 days (interquartile range 4-14).

Almost three-quarters of all patients (988, 72.0\%) presented with 1 or more intrinsic or extrinsic risk factor for HAI (Table 1).

A total of 302 patients underwent a surgical procedure. Among them, 4.0\% were classified as Altemeier surgical contamination classes 3 and 4, 4.0\% had ASA physical status score $3+$ and 


\begin{tabular}{|c|c|c|c|c|c|c|c|c|}
\hline \multirow[t]{2}{*}{ Risk factor } & \multicolumn{2}{|c|}{$\begin{array}{l}\text { Total patients } \\
\quad(n=1373)\end{array}$} & \multicolumn{2}{|c|}{$\begin{array}{l}\text { Infected patients } \\
\qquad(n=74)\end{array}$} & \multicolumn{2}{|c|}{$\begin{array}{c}\text { Uninfected } \\
\text { patients } \\
(n=1299)\end{array}$} & \multicolumn{2}{|c|}{ Statistics } \\
\hline & No. & $\%$ & No. & $\%$ & No. & $\%$ & OR & $95 \% \mathrm{Cl}$ \\
\hline Immunosuppression & 29 & 2.1 & 6 & 8.1 & 23 & 1.8 & 4.1 & $1.51-11.2$ \\
\hline Malnutrition & 72 & 5.2 & 8 & 10.8 & 64 & 4.9 & 2.4 & $1.10-5.20$ \\
\hline Diabetes & 304 & 22.1 & 26 & 35.1 & 278 & 21.4 & 1.9 & $1.13-3.07$ \\
\hline Obesity & 193 & 14.1 & 9 & 12.2 & 184 & 14.2 & 0.7 & $0.34-1.54$ \\
\hline Neutropenia & 8 & 0.6 & 3 & 4.1 & 5 & 0.4 & 7.2 & $1.38-38.1$ \\
\hline Mechanical ventilation & 38 & 2.8 & 9 & 12.2 & 29 & 2.2 & 5.4 & $2.38-12.3$ \\
\hline Parenteral nutrition & 38 & 2.8 & 8 & 10.8 & 30 & 2.3 & 5.2 & $2.30-11.9$ \\
\hline Urinary catheter & 138 & 10.1 & 15 & 20.3 & 123 & 9.5 & 2.3 & $1.23-4.19$ \\
\hline Peripheral venous catheter & 597 & 43.5 & 60 & 81.1 & 537 & 41.3 & 2.6 & $1.58-4.28$ \\
\hline Central venous catheter & 26 & 1.9 & 5 & 6.8 & 21 & 1.6 & 8.6 & $3.79-19.6$ \\
\hline
\end{tabular}

$O R=$ odds ratio; $C I=$ confidence interval.

63.0\% received antibiotic prophylaxis (Table 2).

\section{Overall prevalence}

During the survey, 74 of the 1373 patients were diagnosed with HAI, an overall prevalence of $5.4 \%$ (95\% CI: $4.2 \%-6.6 \%)$. Five patients had more than 1 infection and so the total number of infections was 79: respiratory infections were the most common (45.6\%) followed by urinary tract infections (16.5\%) and surgical site infections (15.2\%).

The median length of hospital stay was significantly higher for infected patients [ 12.5 days (interquartile range 9-19)] and than for noninfected patients [ 7 days (interquartile range $4-13)](P<0.01)$.

\section{Prevalence by department}

The prevalence of HAI was significantly higher in the intensive care units $(8 / 43$, $18.6 \%)$ and neonatal care units (11/54, 20.3\%) compared with other hospital departments $(P<0.001)$. Of the patients in intensive care units, $18 / 43$ (42\%) were under mechanical ventilation, with a high rate of nosocomial pneumonia in this group $(4 / 18,22.2 \%)(P<0.01)$.

\begin{tabular}{|c|c|c|c|c|c|c|c|}
\hline \multirow[t]{2}{*}{ Surgery characteristics } & \multicolumn{2}{|c|}{$\begin{array}{l}\text { Total surgery patients } \\
\qquad(n=302)\end{array}$} & \multicolumn{2}{|c|}{$\begin{array}{l}\text { Infected patients } \\
\quad(n=26)\end{array}$} & \multicolumn{2}{|c|}{$\begin{array}{l}\text { Uninfected patients } \\
\qquad(n=276)\end{array}$} & \multirow[t]{2}{*}{$P$-valuc } \\
\hline & No. & $\%$ & No. & $\%$ & No. & $\%$ & \\
\hline \multicolumn{8}{|l|}{ ASA physical status score } \\
\hline 1 & 214 & 70.9 & 16 & 61.5 & 198 & 71.7 & \multirow{3}{*}{0.4} \\
\hline 2 & 76 & 25.2 & 8 & 30.8 & 68 & 24.6 & \\
\hline $3+$ & 12 & 4.0 & 2 & 7.7 & 10 & 3.6 & \\
\hline \multicolumn{8}{|l|}{ Endoscopy } \\
\hline Yes & 192 & 63.6 & 13 & 50.0 & 179 & 64.9 & \multirow{2}{*}{0.3} \\
\hline No & 110 & 36.4 & 13 & 50.0 & 97 & 35.1 & \\
\hline \multicolumn{8}{|l|}{ Urgency of procedure } \\
\hline Elective & 248 & 82.1 & 2 & 7.7 & 246 & 89.1 & \multirow{2}{*}{0.2} \\
\hline Urgent & 54 & 17.9 & 24 & 92.3 & 30 & 10.9 & \\
\hline \multicolumn{8}{|c|}{ Altemeier contamination class } \\
\hline 1 & 136 & 45.0 & 12 & 46.2 & 124 & 44.9 & \multirow{3}{*}{0.8} \\
\hline 2 & 154 & 51.0 & 12 & 46.2 & 142 & 51.4 & \\
\hline 3 and 4 & 12 & 4.0 & 2 & 7.7 & 10 & 3.6 & \\
\hline \multicolumn{8}{|l|}{ Antibiotic prophylaxis } \\
\hline Yes & 191 & 63.2 & 20 & 76.9 & 171 & 62.0 & \multirow{2}{*}{0.4} \\
\hline No & 111 & 36.8 & 6 & 23.1 & 105 & 38.0 & \\
\hline
\end{tabular}

ASA = American Society of Anesthesiology. 
The prevalence of HAI in surgery departmentswas $8.6 \%(26 / 302)$ (Table $2)$. In this group, urinary tract infection was the most common infection $(9 / 26$ cases). The median length of stay in the surgical department was significantly greater for infected patients [18 days (interquartile range 12-22)] than for noninfected patients $[8$ days (interquartile range $4-15)](P<0.01)$.

\section{Microbiology data}

Microbiology findings were available for only 25 cases of HAI; Gram-negative bacilli were identified in $80 \%(20 / 25)$ of cases, predominately Pseudomonas aeruginosa ( $8 / 20$ cases). Among cases for which microbiology findings were available, 11 cases of antibiotic resistance were detected, 4 in $P$. aeruginosa.

Antibiotics were prescribed for 58 HAI patients, with more than 1 antibiotic for 30 (52\%) of cases. The most frequently used antibiotics were $\beta$-lactamases (45\%), quinolones (15\%) and aminoglycosides (13\%).

\section{Risk factor analysis}

Except for obesity, all the studied risk factors were significantly associated with HAI $(P<0.01)$ (Table 1).

The variables included in the multivariate analysis model were: diabetes, malnutrition, immunosuppression, neutropenia, urinary catheter, central venous catheter, peripheral venous catheter, mechanical ventilation, parenteral nutrition, length of stay and age (divided into classes). The model retained 5 variables independently associated with HAI: diabetes $(\mathrm{OR}=2.0)$, immunosuppression $(\mathrm{OR}=3.3)$, length of stay $(\mathrm{OR}$
$=4.5)$, central venous catheter $(\mathrm{OR}=$ $2.5)$ and peripheral venous catheter $(\mathrm{OR}$ $=10.2)(0.001<P<0.03)($ Table 3$)$.

\section{Discussion}

Although HAI includes infections contracted in ambulatory care departments, our present study was limited to hospital infections. By using a prevalence survey with standard methods [8] and the CDC definition of HAI we are able to compare our study with other prevalence surveys using the same methods and definition. The data collection by a public health doctor and a senior technician in hospital hygiene ensured that the survey was conducted in a consistent and correct manner. The study achieved its objectives in terms of determining the prevalence and associate factors of HAI.

We found that the prevalence of HAI in this region of Tunisia was 5.4\%. This rate is similar to other studies using the same methods $[9,10]$. The highest risk specialties were intensive care and neonatal careunits, where the prevalence of HAI was $18.6 \%$ and $12.7 \%$ respectively. These observations are confirmed by the literature and are the result of several factors related to the patients (such as age, co-morbidities) [11] and the use of invasive procedures, especially central venous catheters [12].

In our study, multivariate analysis shows that diabetes, length of stay, immunosuppression and use of central line and peripheral venous catheters were independent risk factors of HAI. Use of a peripheral venous catheter was the most important risk factor $(\mathrm{OR}=$ 10.2); this may be because less care is taken in insertion of these catheters as staff see it as a simple, everyday activity. We also found a linear correlation between the number of risk factors and the rate of HAI. Similar results were reported by another study [13].

The most frequently infected site was the respiratory tract. It has been demonstrated that pneumonia is the most common nosocomial infection, and respiratory infection is especially common in intensive care units because of the use of artificial ventilation [14]. These results were confirmed in our study, in which $42 \%$ of intensive care unit patients were under mechanical ventilation, with a high rate of nosocomial pneumonia (22.2\%)

Among operated patients, and in accordance with the literature, surgical site infections were the most common infections $[15,16]$. The ASA physical status score, which consists of 5 classes [5], and the Altemeier contamination classification, which separates interventions depending on the degree of cleanliness [6], were predictors of infection risk in surgical patients. Overall, surgical site infections were in fourth position, which demonstrates the attention given to surgical site asepsis to avoid surgical wound infection. However, less attention was given to other important aspects such as urinary catheter insertion under aseptic conditions and regular catheter changes.

The rate of microorganisms, based on microbiological examination, usually exceeds $60 \%[17,18]$. In our case,

\begin{tabular}{lcccc}
\hline Table 3 Independent risk factors of health care associated infections & & & \\
\hline Risk factor & Wald & OR $(\exp \boldsymbol{\beta})$ & $\mathbf{9 5 \%} \mathbf{C I}$ & $\boldsymbol{P}$-value \\
Diabetes & 4.34 & 2.0 & $1.03-3.02$ & 0.03 \\
Length of stay & 24.01 & 4.5 & $2.47-8.24$ & 0.01 \\
Immunosuppression & 5.14 & 3.30 & $1.17-9.27$ & 0.02 \\
Central venous catheter & 12.16 & 2.53 & $1.50-4.28$ & 0.01 \\
Peripheral venous catheter & 27.04 & 10.20 & $4.25-24.5$ & 0.001 \\
\hline
\end{tabular}

$O R=$ odds ratio; $C I=$ confidence interval. 
microbiological testing was performed in only one-third of cases of HAI. This low rate of ordering microbiological testing may be related to the type of infection. Diagnosis of respiratory tract infections (the most frequent type of infection inours tudy) is usually done by clinical suspicion and treated without microbiological confirmation.

Microbiological testing in HAI cases usually shows that Gram-negative bacilli are the most frequent, especially P. aeruginosa [19]. Our study confirmed these findings, with a predominance of Gramnegative bacilli ( $80 \%$ of cases), and 4 out of 11 cases of antibiotic resistance related to $P$. aeruginosa. Other studies have also found high rate of resistant organisms
$[20,21]$. These resistances have multiple causes, especially the inappropriate use of antimicrobial agents [22,23] and can be avoided by appropriate antibiotic therapies based on guidelines informed by local epidemiological data.

\section{Conclusions}

Our findings highlight that HAIs are of concern in the central-east area of Tunisia. The prevalence was significantly higher in the intensive care units and neonatal departments. The most frequent infection sites were respiratory and urinary tract. Risk factors for HAI were diabetes, length of stay, immunosuppression and use of peripheral and central venous catheters. We suggest that prophylactic measures against these infections should be implemented through the establishment of a national prevention strategy.

\section{Acknowledgements}

Special thanks are due to the major public health physicians Besbes Mohamed Hachmi, Bouchahda Mokhtar, Gacem Hbib, Khayach Fathi and the senior technicians in hospital hygiene Ajmi Moufida, Ben Rayana Naziha, Chargui Salwa, Mzoughia Najah for their contribution in this study.

\section{References}

1. Fabbro-Peray $\mathrm{P}$ et al. Mortality attributable to nosocomial infection: a cohort of patients with and without nosocomial infection in a French university hospital. Infection Control and Hospital Epidemiology, 2007, 28:265-272.

2. Groeneveld AB. Risk factors for increased mortality from hospital-acquired versus community-acquired infections in febrile medical patients. American Journal of Infection Control, 2009, 37:35-42.

3. Llata E, Gaynes RP, Fridkin S. Measuring the scope and magnitude of hospital-associated infection in the United States: the value of prevalence surveys. Clinical Infectious Diseases, 2009, 48:1434-1440

4. Jroundi I et al. Prevalence of hospital-acquired infection in a Moroccan university hospital. American Journal of Infection Control, 2007, 35:412-416.

5. Draft guideline for the prevention of surgical site infection, 1998-CDC. Notice. Federal Register, 1998, 63:33168-33192.

6. Garner JS. CDC guideline for prevention of surgical wound infections, 1985. Supersedes guideline for prevention of surgical wound infections published in 1982. (Originally published in November 1985). Revised. Infection Control, 1986, 7:193-200

7. Horan TC, Andrus M, Dudeck MA. CDC/NHSN surveillance definition of health care-associated infection and criteria for specific types of infections in the acute care setting. American Journal of Infection Control, 2008, 36:309-332.

8. Smyth ET et al. Hospital Infection Society Prevalence Survey Steering Group. Four country healthcare associated infection prevalence survey 2006: overview of the results. Journal of Hospital Infection, 2008, 69:230-248.

9. Eriksen HM, Iversen BG, Aavitsland P. Prevalence of nosocomial infections in hospitals in Norway, 2002 and 2003. Journal of Hospital Infection, 2005, 60:40-45.

10. Lahsaeizadeh $\mathrm{S}$, Jafari $\mathrm{H}$, Askarian M. Healthcare-associated infection in Shiraz, Iran 2004-2005. Journal of Hospital Infection, 2008, 69:283-287.

11. Gould IM. Use of active surveillance cultures in intensive care units. Clinical Infectious Diseases, 2009, 48:262-263.
12. Ranasinghe JS, Lee AJ, Birnbach DJ. Infection associated with central venous or epidural catheters: how to reduce it? Current Opinion in Anaesthesiology, 2008, 21:386-390.

13. Paillaud E et al. Relations between undernutrition and nosocomial infections in elderly patients. Age and Ageing, 2005, 34:619-625.

14. Augustyn B. Ventilator-associated pneumonia: risk factors and prevention. Critical Care Nurse. 2007, 27(4):32-39.

15. Brown $\mathrm{S}$ et al. Prevalence and predictors of surgical site infection in Tbilisi, Republic of Georgia. Journal of Hospital Infection, 2007, 66:160-166.

16. De Oliveira AC et al. Surgical site infection in patients submitted to digestive surgery: risk prediction and the NNIS risk index. American Journal of Infection Control, 2006, 34:201-207.

17. Faria $S$ et al. Prevalence Study Group. The first prevalence survey of nosocomial infections in the University Hospital Centre 'Mother Teresa' of Tirana, Albania. Journal of Hospital Infection, 2007, 65:244-250.

18. Gould IM. The epidemiology of antibiotic resistance. International Journal of Antimicrobial Agents, 2008, 32(Suppl. 1):S2-9.

19. Bassetti M, Repetto E. Le infezioni in medicina : rivista periodica di eziologia, epidemiologia, diagnostica, clinica e terapia delle patologie infettive [Diagnostic and therapeutic management of Gram-negative infections]. Le Infezioni in Medicina, 2008, 16(Suppl. 2):22-29.

20. Viktorov DV et al. High-level resistance to fluoroquinolones and cephalosporins in Burkholderia pseudomallei and closely related species. Transactions of the Royal Society of Tropical Medicine and Hygiene, 2008, 102(Suppl. 1):S103-110.

21. Lautenbach $\mathrm{E}$ et al. Imipenem resistance among pseudomonas aeruginosa isolates: risk factors for infection and impact of resistance on clinical and economic outcomes. Infection Control and Hospital Epidemiology, 2006, 27:893-900.

22. Blot $\mathrm{S}$ et al. Measuring the impact of multidrug resistance in nosocomial infection. Current Opinion in Infectious Diseases, 2007, 20:391-396.

23. D'Agata EM et al. Modeling antibiotic resistance in hospitals: the impact of minimizing treatment duration. Journal of Theoretical Biology, 2007, 249:487-499. 